\title{
Individual differences in word recognition latency
}

\author{
BRIAN BUTLER and SYLVIA HAINS \\ Queen's University, Kingston, Ontario K7L 3N6, Canada
}

\begin{abstract}
Previous studies of the effects of word characteristics on word recognition have used orthogonal combinations of word variables and have failed to consider individual differences. The present study examined word naming (Experiment 1) and lexical decision (Experiment 2) tasks using an unrestricted set of words and a correlational analysis. Individual differences were considered using a measure of the subjects' knowledge of the English vocabulary. The results of Experiment 1 indicated that $\log$ (RT) for word naming is affected by word length, word frequency, and the number of syllables in the word; the results of Experiment 2 confirmed the effects of length and frequency but also showed that $\log (\mathrm{RT})$ is a function of the age at which the word is introduced to a child's reading vocabulary. Subjects with a high vocabulary score were more rapid in Experiment 1 but were slower in Experiment 2, compared to subjects with a low vocabulary score. More importantly, high-vocabulary subjects, in both studies, were less affected by word length than the low-vocabulary subjects. The results suggest that subjects do differ in their reading strategy and that word length and word frequency may affect different stages in the word recognition process.
\end{abstract}

Recent interest in the psychology of reading has spawned a number of studies that have attempted to determine the critical stimulus variables affecting word recognition. Various studies have identified three potential variables: number of syllables (e.g., Spoehr \& Smith, 1973), number of letters (i.e., length) (e.g., Frederiksen \& Kroll, 1976), and word frequency (e.g., Forster \& Chambers, 1973). Because these variables are differentially important for various theories of reading (cf. Frederiksen \& Kroll, 1976), a great deal of controversy has arisen over the relative contributions of each variable and over the way in which each affects the word recognition process.

Much of the debate over these variables followed a study by Eriksen, Pollack, and Montague (1970) that suggested that recognition entailed a component of implicit speech. Eriksen et al. found that reaction time (RT) for naming a word increased as the number of syllables in the word increased. Although the effect of syllables was confounded with length of words, a similar effect was found with two-digit numbers. Eriksen et al. concluded, therefore, that implicit speech was a component in perceptual encoding, a view supported by a subsequent study (Colegate \& Eriksen, 1970)

This research was supported by Grant A-9581 from the National Research Council of Canada to the senior author. Experiment 1 formed part of a BA honors thesis submitted to Queen's University by the junior author. Both authors wish to thank Don Watts and the Staff of Queen's STATLAB for their assistance with the data analysis, and D. J. K. Mewhort and A. J. Campbell for reading a preliminary draft. Requests for reprints should be sent to Brian Butler, Department of Psychology, Queen's University, Kingston, Ontario K7L 3N6, Canada. showing that the number of geometric forms reported from a brief display depended on the number of syllables in the name assigned to each form. The effect with digits was confirmed by Klapp (1971), who demonstrated a syllable effect on RT when subjects had to compare two sets of two-digit numbers without overtly naming the digits.

Subsequent studies have shown some important limitations to the syllable effect but have not yielded entirely consistent results. Klapp, Anderson, and Berrian (1973) replicated the syllable effect with a picture naming task but were unable to find the effect with RT in a word-nonword decision task. Accordingly, Klapp et al. concluded that the syllable length affected the preparation of a covert verbal response but did not affect initial encoding and recognition, a view that is inconsistent with the previous observation (Klapp, 1971) that the number of syllables in a two-digit number affected same-different RT. The argument that syllables affect the overt response is also incompatible with results reported by Henderson, Coltheart, and Woodhouse (1973). They demonstrated that the syllable effect with two-digit numbers was slight, and they suggested that it could be due to faster processing of decade units. While the Henderson et al. results are incompatible with Klapp et al., they do support the study by Spoehr and Smith (1973), which failed to show an effect of syllables with the recognition threshold for digits but found a syllable effect with the recognition accuracy of five-letter words. Spoehr and Smith (1973) returned to the proposition that syllable structure affected word encoding but noted that syllables were confounded with vocalic center groups and suggested that the latter affected a unitization stage in recognition. 
The syllable effect, therefore, may indicate that subjects use a phonetic coding strategy with words but should depend on the syllables actually being represented in the stimulus structure and should be closely correlated with word length. This interpretation could not explain a syllable effect with picture naming (Klapp et al., 1973).

Although many other researchers have postulated phonetic or phonemic recoding (e.g., Meyer, Schvaneveldt, \& Ruddy, 1974; Rubenstein, Lewis, \& Rubenstein, 1971), some studies suggest that this either is unnecessary or occurs following word recognition. Forster and Chambers (1973) found that word naming is dependent on word frequency and correlates closely with lexical decision time but that these relations do not hold for nonwords. They conclude that decisions about word meaning occur prior to, and facilitate, phonemic encoding. A similar conclusion was reached by Frederiksen and Kroll (1976) in a study that considered the independent effects of syllables, length, and frequency on RT for naming and for lexical decisions. Their results showed that word naming was not affected by syllable structure but that it was affected by length and frequency. In contrast, lexical decision time was not affected by syllables or length but did depend on frequency. Both the Forster and Chambers (1973) and the Frederiksen and Kroll (1976) studies agree with Klapp et al. (1973) in failing to show a syllable effect with lexical decisions, but all three are contrary to an unpublished study by Mewhort and Beal (Note 1). These researchers did find an effect of syllable structure with an "animal-vegetable" classification task, but they varied the word characteristics over a much wider range. Forster and Chambers (1973) and Frederiksen and Kroll (1976) considered only oneor two-syllable words with four to six letters, while Klapp et al. (1973) used five-letter words only. The results with lexical decision tasks are important because they have been taken as support for nonphonemic models of word recognition.

All of the studies mentioned above share two important limitations that may affect the generality of their conclusions. The primary shortcoming is that the sample of words is necessarily limited by the experimental design. In most cases, word variables have been combined orthogonally despite the fact that such variables are closely correlated in normal language (Carroll \& White, 1973). Because of the intercorrelations, it is impossible to select a wide range of values on any single dimension, and it is impossible to avoid sampling differences between the cells in an orthogonal design. If a design includes a cell for four-letter twosyllable words, then the only vegetable name in that category will be OKRA. ${ }^{\prime}$ If the design also includes frequency as a variable, then some cells must contain no vegetable names.
While design limitations are a problem, a far more serious problem may be the consistent failure to consider individual differences. All of the studies mentioned earlier assume that subjects adopt and maintain a common reading strategy. This is difficult to justify; college freshmen are notoriously variable in their reading habits and in their use of English (Norman, 1977). In addition, Browning-Crinion, Dolmetsch, and Mayzner (1978) have reported substantial individual differences in word recognition accuracy. Individual differences may be especially pertinent to studies of the effects of word variables since the skill of the reader may interact with word characteristics.

LaBerge and Samuels (1974) have proposed a theory of automatic reading that argues that skilled readers have several options in identifying a word. An experienced reader may rely on a phonological recoding of a word or on unitized spelling patterns, or he may recognize the word directly from visual features. Fluent readers, therefore, become less dependent on the specific orthographic or phonemic features of a word. It is interesting to note that Henderson, Coltheart, and Woodhouse (1973) failed to show a syllable effect in a study whose sample included four faculty members. Similarly, Fredericksen and Kroll (1976) mixed graduate and undergraduate students and failed to show a syllable effect.

The present studies examine individual differences and the effect of word characteristics using an essentially unrestricted sample of words. The first experiment used a word naming task in which subjects were required to pronounce a word as rapidly as possible after the word was presented; the second involved a lexical decision task in which the subject had to decide whether a stimulus was a word or a nonword as rapidly as possible. For both studies, the words were selected nonsystematically from the Kučera-Francis (1967) word list, with no attempt to manipulate word variables orthogonally. Since the LaBerge and Samuels (1974) model suggests that individual differences are due to differential experience with words, each subject was given a brief vocabulary test using words that did not appear as stimuli. For both experiments, RT was the dependent variable and a regression analysis was used to assess both the word variables and the vocabulary measure as predictors of RT.

The vocabulary test requires some justification. The test consisted of two installments of "It Pays to Increase Your Word Power" (1976a, 1976b) from the Reader's Digest. This test was selected because it is designed for relatively skilled readers and, therefore, should be suitable for a college population. The words used in the test are listed in Table 1. An independent study showed that the results for this test correlated $+.65(\mathrm{df}=84$, $\mathrm{p}<.01)$ with the Mill Hill Vocabulary Scale, Senior, Form 1 (Raven, 1943). 
Table 1

Words Used in the Vocabulary Test

\begin{tabular}{llll}
\hline Pliable & Genre & Pedigree & Canard \\
Format & Contrive & Apian & Zodiacal \\
Plangent & Predominant & Pecuniary & Congregate \\
Nonpareil & Subliminal & Cornucopia & Leviathan \\
Randy & Sensuous & Exuberant & Ferret \\
Melodrama & Durable & Behemoth & Vermin \\
Entice & Mire & Preen & Vulpine \\
Affluent & Axiom & Caper & Bugbear \\
Enunciate & Reminiscent & Lionize & Halcyon \\
Valiant & Conventional & Harangue & Gadfly \\
\hline
\end{tabular}

\section{EXPERIMENT 1}

\section{Method}

Subjects. The subjects were eight male and four female students enrolled in introductory psychology at Queen's University. All subjects spoke English only,

Materials. Stimuli for the experiment consisted of 236 words selected from the Kučera and Francis (1967) word lists. All words began with one of six consonants: $C, N, R, T, W$, or $S$. The words were selected nonsystematically with the restriction that approximately the same number of words began with each consonant and that about equal numbers were selected for each syllable length. All stimuli were printed on white cardboard using black uppercase Letraset Instant Lettering (Number 187). As viewed by the subject, the words subtended horizontal visual angles ranging from $48 \mathrm{~min}$ for 2 -letter words to $4 \mathrm{deg} 1 \mathrm{~min}$ for 14-letter words.

Three characteristics were assessed for each word. Word length was defined as the number of letters in the word. The number of syllables was measured using the unabridged version of Webster's Third New International Dictionary of the English Language (1966). Word frequency was measured in terms of the scientific frequency index (SFI), which is essentially a logarithmic transformation of the word-frequency count listed by Kucera and Francis (1967). The SFI was used because Carroll and White (1973) had previously used the same transformation to produce a linear relation with their RT measures. A summary of the characteristics for the words and the formula for SFI are listed in Table 2.

All stimuli were presented on a Gerbrands three-field Harvard tachistoscope (Model T-3A). An electronic timer was connected to the auxilliary channel of the tachistoscope timer so that onset of the stimulus field would trigger the timer. A Sony microphone mounted below the viewing port on the tachistoscopc provided the input to a voice key that shut off the timer. The timer recorded the time in milliseconds from the onset of the visual stimulus to the onset of the subjects' verbal response. Both the timer and the voice key were constructed locally.

The vocabulary test administered to each subject was described earlier. The test consisted of 40 words with four alternatives for the definition. Subjects were required to choose an answer for each word, and the score was simply the number of words correct. No attempt was made to correct for guessing.

Table 2 Characteristics of Words Used in Experiment 1

\begin{tabular}{lrrr} 
& \multicolumn{1}{c}{ Range } & Mean & \multicolumn{1}{c}{ SD } \\
\hline Number of Syllables & $1-5$ & 2.38 & 1.150 \\
Length & $2-14$ & 7.26 & 2.740 \\
Frequency in SFI & $40-84.2$ & 50.67 & 8.936 \\
\hline
\end{tabular}

Note-SFI $=[(\log \times F / 1,000,000)+10] \times 10$, where $F=$ the number of occurrences in a sample of 1,000,000 words.
Procedure. Each subject was told that the task involved naming a word as rapidly as possible after it had been presented. Each subject was familiarized with the voice key and was given 20 practice trials with a different set of words. A trial began with a verbal "ready" signal followed by a 1.5-sec presentation of the stimulus illuminated at approximately $17 \mathrm{~cd} / \mathrm{m}^{2}$. Between trials a small fixation dot was illuminated at approximately $17 \mathrm{~cd} / \mathrm{m}^{2}$. The latency of the subject's response was measured in milliseconds for each of the 236 words. All stimuli were presented in random order. If the subject either failed to respond or seriously mispronounced a word, the stimulus was presented again later in the test series. The vocabulary test was administered at the end of the session.

\section{Results and Discussion}

Because subjects made errors on less than $1 \%$ of the trials and error stimuli were repeated, $236 \mathrm{RT}$ scores were collected for each of the 12 subjects. Each score represented the time in milliseconds from the onset of the word to the onset of the verbal response. An initial inspection of each subject's data showed considerable skew in the frequency distributions for RT and nonlinear relationships between RT and the word variables. Both problems were circumvented by using a logarithmic transformation. A reciprocal transformation was used by Carroll and White (1973) for much the same reason. Since the study was designed to assess the effects of the word variables and individual differences, the data analysis consisted of a series of multiple regressions of $\log (\mathrm{RT})$ as a function of the three word variables, the vocabulary scores of the subjects, and three additional variables. The three additional variables represented the interactions of vocabulary with each of the word variables and were obtained by taking the products of vocabulary and syllables (SYLX VOC), frequency (SFI $X$ VOC), and length (LEN X VOC). Within a linear equation describing a set of results, the interaction between two variables in always represented by a crossproduct of those variables (cf. Mendenhall, 1968, p. 93). Although the words did differ in their initial consonants, this had a minor effect on the latency scores and was not included in the regression analyses. ${ }^{2}$

Table 3 presents the intercorrelation matrix for the seven independent variables and $\log (\mathrm{RT})$ for each subject. As expected, the correlations among the word variables indicate that these factors are closely correlated in normal English. These values are close to those reported by Carroll and White (1973). Table 3 also shows that $\log (\mathrm{RT})$ is related to the number of syllables in the word $(\mathrm{r}=+.25)$, the frequency of the word $(r=-.20)$, and the length of the word $(r=+.27)$. Individual differences appear in two forms. First, individuals with high vocabulary scores appear to react more rapidly since $\log (\mathrm{RT})$ and vocabulary are inversely correlated $(r=-.36)$. Second, the correlations between $\log (\mathrm{RT})$ and the three variables that reflect interactions between the vocabulary scores and the word variables suggest that subjects may differ in the extent to which they are affected by each word variable. The possible 
Table 3

Intercorrelation Matrix for Variables in Experiment 1

\begin{tabular}{|c|c|c|c|c|c|c|c|c|}
\hline & $\log (\mathrm{RT})$ & Syllables & SFI & Length & Vocabulary & SYL $\times$ VOC & SFI $\times$ VOC & LEN $\times$ VOC \\
\hline $\log (\mathrm{RT})$ & 1.00 & .25 & -.20 & .27 & -.36 & .11 & -.41 & .09 \\
\hline Syllables & & 1.00 & -.37 & .85 & .00 & .94 & -.17 & .77 \\
\hline SFI & & & 1.00 & -.45 & .00 & -.35 & .45 & -.41 \\
\hline Length & & & & 1.00 & .00 & .79 & -.20 & .91 \\
\hline Vocabulary & & & & & 1.00 & .31 & .89 & .39 \\
\hline SYL $\times$ VOC & & & & & & 1.00 & .12 & .86 \\
\hline $\mathrm{SFI} \times \mathrm{VOC}$ & & & & & & & 1.00 & .16 \\
\hline LEN $\times$ VOC & & & & & & & & 1.00 \\
\hline
\end{tabular}

individual differences in the effects of the word variables also appeared when the intercorrelation matrices were calculated for each subject individually. With individual subjects, the correlation between $\log (\mathrm{RT})$ and the number of syllables ranges from .17 to .48 , the correlation with frequency ranges from -.13 to -.39 , and the correlation with length ranges from .16 to .54 . The discrepancies between the values for individual subjects and the correlations shown in Table 3 could reflect normal sampling error or could indicate differences in the extent to which subjects are affected by the word variables.

A series of five multiple regressions, based on the matrix in Table 3, are shown in Table 4. The initial analysis with all seven variables indicated that only length, frequency, and the product of vocabulary and length (LEN $\times$ VOC) were effective predictors of $\log (\mathrm{RT})$. Dropping the number of syllables as a predictor (Analysis 2) had relatively little effect on the proportion of variance $\left(R^{2}\right)$ accounted for $[F(1,1812)=.61]$, but did increase the importance of vocabulary and SYLXVOC as predictors. The comparisons between Analyses 2 and 3 and Analyses 4 and 5 confirm that syllables must be included as a predictor in some form. The comparison of Analyses 2 and 3 shows a decrease in $R^{2}$ when SYL $\times$ VOC is omitted $[F(1,1815)=7.32, p<.01]$, while the latter shows a decrease in $R^{2}$ when the syllables variable is omitted $[F(1,1816)=7.81, p<.01]$. The results of the regression analyses, therefore, substantiate
Fredericksen and Kroll's (1976) claim that length and frequency affect word naming RT, but also indicates that the number of syllables is an important determinant. The regression analyses also confirm that individual differences appear in two forms. In the first three analyses, the vocabulary score almost reaches significance as a predictor of $\log (\mathrm{RT})$ and does in the final three analyses when SYL $X$ VOC and SFI $X$ VOC are omitted from the equation. Since the sign for the B weight for vocabulary is negative, this confirms the observation from Table 3 that high-vocabulary subjects reacted more rapidly. The results, however, also indicate that high-vocabulary subjects were less affected by word length. The product LEN $X$ VOC remains a significant predictor for the first five analyses, and a comparison of Analyses 4 and 6 shows a substantial decrease in $R^{2}$ when this variable is dropped from the equation $[F(1,1816)=36.45, p<.001]$. The most parsimonious equation that accounts for the largest proportion of variance is represented in Analysis 4; it included the main effects of the word variables and the vocabulary scores plus the interaction of length and vocabulary.

The interaction of vocabulary score and the three word variables is illustrated in Figure 1. For each subject, three correlation coefficients were calculated to indicate the relationship between $\log (\mathrm{RT})$ and each of the word variables with the effect of the other two word variables partialled out. Figure 1 shows the partial correlation coefficients for $\log (\mathrm{RT})$ with syllables, frequency, and length plotted as a function of the

Table 4

Multiple-Regression Analy ses for $\log (\mathrm{RT})$ in Experiment 1

\begin{tabular}{|c|c|c|c|c|c|c|c|c|c|c|c|c|}
\hline & \multicolumn{2}{|c|}{ Analy sis 1} & \multicolumn{2}{|c|}{ Analysis 2} & \multicolumn{2}{|c|}{ Analysis 3} & \multicolumn{2}{|c|}{ Analysis 4} & \multicolumn{2}{|c|}{ Analysis 5} & \multicolumn{2}{|c|}{ Analysis 6} \\
\hline & B & $\mathrm{F}$ & B & F & B & F & B & $\mathrm{F}$ & B & $\mathrm{F}$ & B & $F$ \\
\hline Syllables & .04 & .61 & & & & & .021 & $7.81^{*}$ & & & .021 & $7.72^{*}$ \\
\hline Length & .065 & $10.15^{*}$ & .07 & $44.89^{*}$ & .077 & $44.79 *$ & .076 & $50.74 *$ & .084 & $64.88^{*}$ & .015 & $20.34 *$ \\
\hline SFI & -.007 & $4.02 *$ & -.007 & $3.94 *$ & -.007 & 3.93* & -.003 & $28.89 *$ & -.003 & $28.03 *$ & -.003 & $28.53 *$ \\
\hline Vocabulary & -.027 & 2.36 & -.016 & 3.17 & -.017 & 3.27 & -.006 & $4.41^{*}$ & -.006 & $4.39^{*}$ & -.025 & $475.35^{*}$ \\
\hline SYL $\times$ VOC & -.001 & .12 & .001 & $7.32 *$ & & & & & & & & \\
\hline LEN $\times$ VOC & -.002 & $6.23 *$ & -.003 & $28.54^{*}$ & -.002 & $23.59 *$ & -.003 & $36.45^{*}$ & -.003 & $36.36^{*}$ & & \\
\hline SFI $\times$ VOC & .001 & 1.36 & .000 & 1.31 & .000 & 1.34 & & & & & & \\
\hline $\begin{array}{l}\text { Constant } \\
\mathrm{R}^{2}\end{array}$ & $\begin{array}{l}7.279 \\
.2238\end{array}$ & & $\begin{array}{l}6.838 \\
.2236\end{array}$ & & $\begin{array}{l}6.838 \\
.2112\end{array}$ & & $\begin{array}{c}6.595 \\
.2234\end{array}$ & & $\begin{array}{l}6.589 \\
.2212\end{array}$ & & $\begin{array}{l}7.23 \\
.2133\end{array}$ & \\
\hline
\end{tabular}

${ }^{*} p<.05(d f=1,2824)$. 

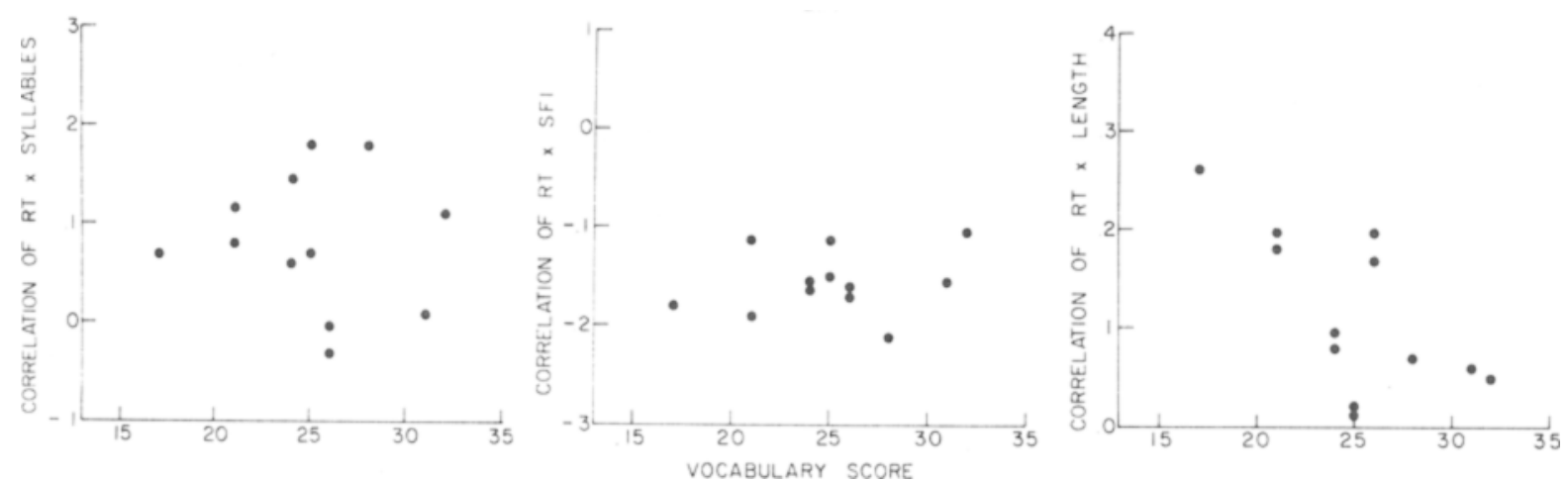

Figure 1. Partial correlations between $\log (\mathrm{RT})$ and each word variable according to the vocabulary scores for subjects in Experiment 1.

subject's vocabulary score. The partial correlations of $\log (\mathrm{RT})$ and syllables show considerable variability but no systematic relationship to vocabulary $[\mathrm{r}(11)=-.03]$. The partial correlations with frequency appear to show less variability across subjects but, again, do not appear closely related to the vocabulary measure $[\mathrm{r}(11)=-.19]$. The partial correlations with length, however, are related to the subject's vocabulary scores $[\mathrm{r}(11)=-.65, \mathrm{p}<.02]$. For subjects with high vocabulary scores, length is not a good predictor of $\log (\mathrm{RT})$; for low-vocabulary subjects, $\log (\mathrm{RT})$ is closely related to word length.

Figure 2 provides a further illustration of the interaction between length and vocabulary in terms of RT, rather than $\log (\mathrm{RT})$. Since two subjects were tied for the median vocabulary score, a median split of subjects into two groups was not possible. Instead, Figure 2 shows the mean RT for each word length for seven high-vocabulary subjects and five low-vocabulary subjects. The high-vocabulary subjects responded more rapidly and were less affected by word length.

The present results certainly confirm that at least two variables, word length and word frequency, are

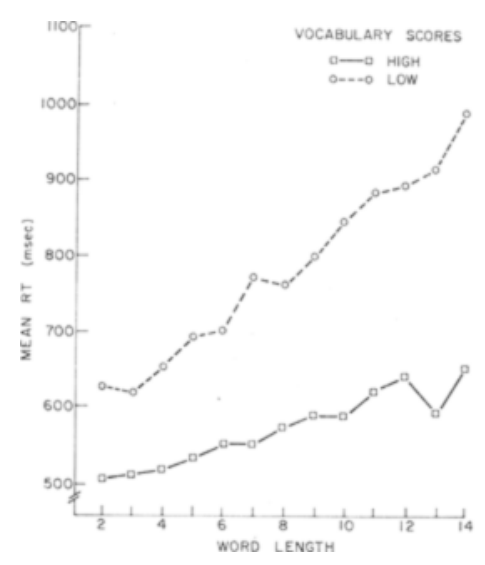

Figure 2. Mean RT for high- $(n=7)$ and low- $(n=5)$ vocabulary subjects in Experiment 1. important determiners of word naming latency. The number of syllables in a word also appears to have some effect, although this is open to question because of the relatively ambivalent effect of syllables in the regression analyses. With the present results, the effect of syllables is difficult to assess because syllables are closely correlated with length and syllables have only five discrete levels compared with 13 for length and continuous variability for frequency. The most important aspect of the present results, however, is the differences among subjects and the fact that the differences interact with word length but not with word frequency. The present pattern of results raises the possibility that vocabulary and length affect one stage in the word recognition process while word frequency affects another stage. As Sternberg (1969) pointed out, if two variables interact in affecting RT, then it is likely that these variables affect a common stage of information processing. If two variables do not interact (i.e., their effects are additive), it is more likely that they affect different stages. This interpretation suggests that vocabulary and length combine to affect a different stage from that affected by word frequency. The effect of syllables cannot be included, of course, because it is not clear from the regression whether syllables or SYL X VOC is the best predictor of $\log (\mathrm{RT})$.

\section{EXPERIMENT 2}

Since the previous experiment used a word naming task, the individual differences that were observed may indicate simply that subjects with high vocabulary scores are more facile at pronouncing words, especially long words. The word naming task must consist of a stage of word recognition followed by a stage of response preparation. In line with the additive factors argument, word length and vocabulary may affect response preparation but may have little to do with the actual recognition of the word. Such an interpretation would agree completely with results obtained by Fredericksen and Kroll (1976) showing an effect of length with a 
word naming task but no effect with a lexical decision task. In order to test this possibility, the present experiment repeated the basic design of Experiment 1 using a lexical decision task in which subjects were shown words or nonwords and had to classify the stimuli as rapidly as possible.

The syllables variable was not included as a predictor for this experiment. It was dropped principally because the previous analysis showed that the effect of syllables cannot be clearly separated from length with a random sample of words. Length was included and is the more pertinent variable, since Fredericksen and Kroll (1976) did not find an effect of word length on lexical decision RT. Instead of syllables, the age of acquisition was included with length and frequency in the analysis of response latencies. Age of acquisition refers to the approximate age of the child when the word is introduced to the child's reading vocabulary in school. This value was determined by assuming that the child was 6 years old in Grade 1 then determining the earliest grade level at which the word appeared with a frequency greater than one. The frequency with which words appear in the reading vocabulary for different grade levels is contained in the frequency norms compiled by Carroll, Davies, and Richman (1971). The age of acquisition was included as a variable because it has been shown to be a principal determiner of picture naming latency (Carroll \& White, 1973) and is not as closely correlated with either frequency or length $(r=.70$ and .55 , respectively, according to Carroll \& White $)$ as syllables is with length $(r=.85)$.

A more important reason for including age of acquisition as a variable is a possible similarity between the effects of age and word frequency. Carroll and White (1973) have argued that age affects picture naming latency by determining the time for information retrieval from memory. Similarly, Fredericksen and Kroll (1976) attributed the effect of word frequency in word naming to processes of memory access and search. If these variables do affect a common stage, and that stage of recognition is different from the stage affected by length and vocabulary, then the individual differences in the effects of age and frequency should be minimal.

\footnotetext{
Method

Subjects. The subjects were 12 students en rolled in introductory psychology. All spoke English only. The vocabulary test described earlier was administered to the class prior to subject selection, and the subjects were selected so as to sample as wide a range of vocabulary scores as possible.

Materials. The word stimuli used in the previous experiment were again used in this task, but the set was reduced to 150 words by discarding 86 items randomly. The characteristics of the words are summarized in Table 5. A set of 150 nonword stimuli was prepared by choosing sequences of letters from the fourth-order approximations to English listed by Hirata and Bryden (1971). The length of the fourth-order approximations was matched to the length of the words so that each length was represented equally in each sample. Since the sequences
}

Table 5

Characteristics of Words Used in Experiment 2

\begin{tabular}{lrrl}
\hline & Range & Mean & SD \\
\hline Age of Acquisition & $6-16$ & 10.96 & 2.35 \\
Length & $2-13$ & 7.49 & 2.90 \\
Frequency in SFI & $40-84.2$ & 51.31 & 9.65 \\
\hline
\end{tabular}

presented by Hirata and Bryden have a maximum of 10 letters, the longer nonwords were prepared by splicing two sequences so that the two letters that were paired at the splice represented an acceptable pair of letters in normal English. The nonwords were printed in the same manner as the words in the previous study.

The apparatus used to present the materials was the same as before. For this task, a set of two pushbuttons connected to microswitches was substituted for the voice key. An electronic timer, connected to the tachistoscope, could be terminated by the pushbuttons. A light, connected to the pushbuttons through a separate circuit, indicated which response had been given on each trial.

Procedure. Each subject was told that either a word or a nonword would appear on each trial and he or she was to classify the stimulus, as quickly as possible, by pushing one of the two buttons. Different hands were used for each response and the button for the dominant hand was used to indicate a word as stimulus. Twenty practice trials were given, with an extra series of stimuli prior to the 300 test trials. Stimuli were presented in the same manner as in the previous experiment. On each trial, the response and the latency between stimulus onset and the response were recorded. All stimuli were presented in random order. As in the previous study, if the subject made an error in responding, the stimulus was repeated later in the test series. Errors occurred on only $1.3 \%$ of the trials.

The vocabulary test was not administered during the test session but had been given to all subjects previously in a group situation. These subjects were members of the class that was given both the present vocabulary test and the Mill Hill test.

\section{Results and Discussion}

A total of 300 latency scores were collected for each of the 12 subjects. An inspection of the data indicated that a transformation was necessary, so all scores were converted to $\log (\mathrm{RT})$. The $\log (\mathrm{RT})$ scores for the words were submitted to a series of multiple regressions to assess the effects of the three word variables (i.e., age, frequency, and length), the subjects' vocabulary scores, and three variables formed by the product of each of the word variables and the vocabulary scores. The $\log (\mathrm{RT})$ scores for nonwords was regressed against length, vocabulary, and the product LEN $\times$ VOC.

Table 6 presents the intercorrelation matrix for the seven variables used to predict $\log (\mathrm{RT})$ for the words $\log (\mathrm{RT})$ is correlated with both length $(\mathrm{r}=.28)$ and frequency $(r=-.32)$, as in the previous experiment. The present results also show that $\log (\mathrm{RT})$ is correlated with age of acquisition $(r=.33)$. As expected, age of acquisition is correlated with both frequency $(\mathrm{r}=-.55)$ and length $(\mathrm{r}=.58)$, but not as closely as length and syllables $(r=.85)$ in the previous study. It should be noted that the correlation between $\log$ (RT) and the rocabulary score for subjects is positive in Table 6 $(\mathrm{r}=.17)$, although the correlation was negative 
Table 6

In tercorrelation Matrix for Word $\log (\mathrm{RT})$ and Variables in Experiment 2

\begin{tabular}{|c|c|c|c|c|c|c|c|c|}
\hline & $\log (\mathrm{RT})$ & AGE & SFI & Length & Vocabulary & AGE $\times$ VOC & $\mathrm{SFI} \times \mathrm{VOC}$ & LEN $\times$ VOC \\
\hline $\log (\mathrm{RT})$ & 1.00 & .33 & -.32 & .28 & .17 & .33 & -.14 & .28 \\
\hline AGE & & 1.00 & -.55 & .58 & .00 & .92 & -.39 & .52 \\
\hline SFI & & & 1.00 & -.45 & .00 & -.51 & .71 & -.38 \\
\hline Length & & & & 1.00 & .00 & .53 & -.31 & .89 \\
\hline Vocabulary & & & & & 1.00 & .36 & .70 & .43 \\
\hline $\mathrm{AGE} \times \mathrm{VOC}$ & & & & & & 1.00 & -.12 & .64 \\
\hline SFI $\times$ VOC & & & & & & & 1.00 & .01 \\
\hline LEN $\times$ VOC & & & & & & & & 1.00 \\
\hline
\end{tabular}

Table 7

Multiple-Regression Analyses for $\log (\mathrm{RT})$ to Words in Experiment 2

\begin{tabular}{|c|c|c|c|c|c|c|}
\hline & \multicolumn{2}{|c|}{ Analysis 1} & \multicolumn{2}{|c|}{ Analysis 2} & \multicolumn{2}{|c|}{ Analysis 3} \\
\hline & B & $\mathrm{F}$ & B & $\mathrm{F}$ & B & $\mathrm{F}$ \\
\hline AGE & .045 & $4.93 *$ & .022 & $36.84 *$ & .022 & $36.47 *$ \\
\hline Length & .046 & $8.93 *$ & .063 & $25.81 *$ & .01 & $48.8^{*}$ \\
\hline SFI & -.01 & $5.03 *$ & -.006 & $49.3 *$ & -.006 & $11.83^{*}$ \\
\hline Vocabulary & .014 & 1.3 & .023 & $36.76^{*}$ & .008 & $28.85^{*}$ \\
\hline$A G E \times V O C$ & -.001 & 1.29 & & & & \\
\hline $\mathrm{LEN} \times \mathrm{VOC}$ & -.001 & $5.75^{*}$ & -.002 & $19.49 *$ & & \\
\hline SFI $\times$ VOC & .000 & .96 & & & & \\
\hline Constant & 6.28 & & 6.05 & & 6.44 & \\
\hline $\mathrm{R}^{2}$ & .168 & & .166 & & .157 & \\
\hline
\end{tabular}

${ }^{*} p<.05(d f=1,1792)$.

$(r=-.36)$ in the previous experiment. Subjects with high vocabulary scores, therefore, took longer to make a lexical decision than those with low vocabulary scores.

Three of the multiple regressions for the $\log (\mathrm{RT})$ scores for words are shown in Table 7 . The pattern with the analyses is very similar to those in the previous experiment. All three analyses demonstrate that performance is strongly affected by all three word variables. The differences between subjects appear as a main effect of vocabulary and the interaction between vocabulary and length (i.e., LEN $\times$ VOC). The initial analysis did not show significance for vocabulary, but the second analysis, with AGE $X$ VOC and SFI $X$ VOC deleted, did show a substantial proportion of variance attributed to the vocabulary variable. Omitting AGE $X$ VOC and SFI X VOC did not produce any substantial decrease in the proportion of variance accounted for by the equation $[F(2,1794)=1.876]$. Dropping LEN $X$ VOC from the equation (Analysis 3), however, did produce a substantial decrease in $\mathrm{R}^{2}$ $[F(1,1794)=19.49, p<.01] . \quad$ As in the previous experiment, the simplest equation, shown in Analysis 2, for predicting $\log (\mathrm{RT})$ includes the three word variables, the vocabulary scores of the subjects, and the product of vocabulary and length. In this study, subjects with high vocabulary scores take somewhat longer to react, compared to low-vocabulary subjects, but are less affected by word length than the low-vocabulary subjects. The relation between vocabulary and length is represented in Figure 3, which shows mean RT as a function of length for high- and low-vocabulary subjects.

For the purpose of representing the data in Figure 3, the 12 subjects were divided into two equal groups using a median split on the vocabulary scores.

The slightly longer RT to the words for highvocabulary subjects may indicate that these subjects set a more stringent criterion for deciding whether a stimulus was a word. This is certainly suggested by the RT scores for the nonwords. Table 8 presents two regression analyses for $\log (\mathrm{RT})$ to the nonwords. In this case, the high-vocabulary subjects are slower at reacting, indicated by a positive sign for $\mathrm{B}$, and both high- and low-vocabulary subjects appear to be affected equally by word length. The product LEN $\times$ VOC does not account for a significant proportion of variance with the $\log (\mathrm{RT})$ scores for the nonwords $[\mathrm{F}(1,1796)=.09]$. Figure 4 shows the mean $\log (\mathrm{RT})$ for the nonwords with the two vocabulary groups using the same median split as in Figure 3 . The high-vocabulary subjects, therefore, took considerably longer to decide that a fourth-order approximation to English was not a real word in English.

\section{CONCLUSIONS}

In Experiment $1, \log (\mathrm{RT})$ in the word naming task was determined by the length, frequency, and number of syllables of the words. Because the words were selected at random, a substantial range of values was tested for each word. The range for syllables was much larger than the range tested by Fredericksen and Kroll (1976), and this may explain why the results with Fredericksen and

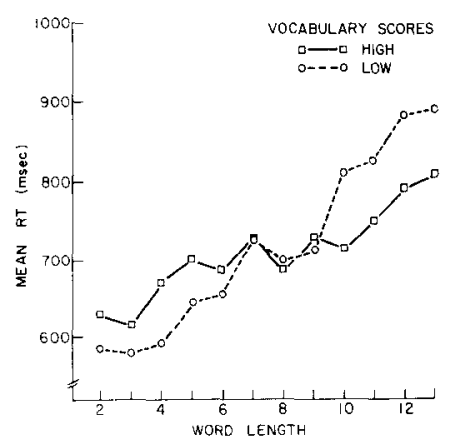

Figure 3. Mean RT to words for high- $(n=6)$ and low- $(n=6)$ vocabulary subjects in Experiment 2. 
Table 8

Multiple-Regression Analyses for $\log (\mathrm{RT})$ for Nonwords in Experiment 2

\begin{tabular}{lccccc}
\hline & \multicolumn{2}{c}{ Analysis 1 } & & \multicolumn{2}{c}{ Analysis 2 } \\
\cline { 2 - 3 } \cline { 5 - 6 } & $\mathrm{B}$ & $\mathrm{F}$ & & $\mathrm{B}$ & $\mathrm{F}$ \\
\hline Length & .017 & 1.27 & .023 & $61.08^{*}$ \\
Vocabulary & .024 & $24.52^{*}$ & .025 & $211.17^{*}$ \\
LEN $\times$ VOC & .000 & .09 & & \\
Constant & 6.04 & & 6.01 & \\
$\mathrm{R}^{2}$ & .1316 & & .1315 \\
\hline
\end{tabular}

${ }^{*} p<.05(d f=1,1796)$.

Kroll's naming task failed to show an effect of number of syllables. Similarly, the results of Experiment 2 clearly show an effect of word length and word frequency on $\log (\mathrm{RT})$ with a lexical decision task. In this case, word length included a range from 2 to 13 letters. Previous studies by Fredericksen and Kroll (1976) and Terry, Samuels, and LaBerge (1976) failed to show an effect of word length with a lexical decision task but included a much smaller range: four to six letters with the former and three to six with the latter.

The most important aspect of the results is the difference in the effect of word length with high-and low-vocabulary subjects. Both the word naming and the lexical decision tasks show the same effect: Word length is a better predictor of $\log (\mathrm{RT})$ for subjects with low vocabulary scores than it is for subjects with high vocabulary scores. Since the interaction occurs with both tasks, it appears to be independent of the response and must involve the word recognition process that is common to both tasks. The interaction is especially pertinent to theories of word recognition because different theories make contrary predictions about the effects of word length. Terry et al. (1976) used word length to discriminate between two general classes of models. These authors discriminated between hierarchical models, which assume that individual letters are identified prior to word recognition, and two-level

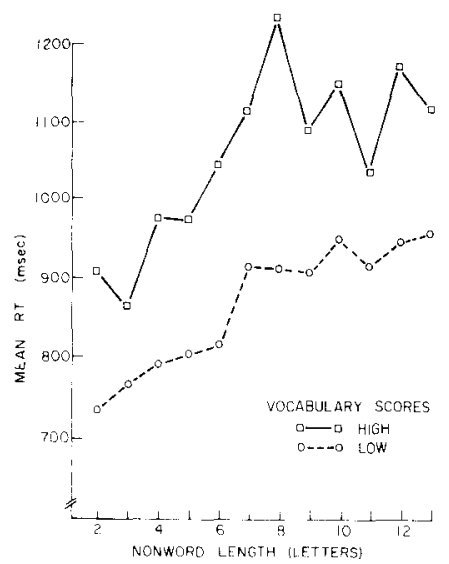

Figure 4. Mean RT to nonwords for high- $(n=6)$ and low$(n=6)$ vocabulary subjects in Experiment 2. models, which assume that the word code is activated directly from the output of a stage of feature analysis (e.g., Smith, 1971). These models make quite different predictions about the effect of word length. As Terry et al. (1976) have pointed out, "if latency increases linearly and at a relatively high rate with word length, this would suggest that the process entails a serial scan of the letters, supporting a hierarchical model. If, on the other hand, latency is constant across the number of letters in the word, this would appear to suggest unitary processing of the word, supporting a two-level model. If latency increases only slightly with word length, this would seem to support a hierarchical model in which letters are processed in parallel"' (p. 577-578).

Because the present results show a change in the slope of the latency-length relationship as a function of the subject's vocabulary score, it seems likely that the highvocabulary subjects are adopting a more holistic reading strategy than the low-vocabulary subjects. Of course, it is impossible to determine from the present results whether high-vocabulary subjects are using a completely unique reading strategy, but the results at least suggest that they are dealing more efficiently with long words. One major implication of the present results is that any experiment that is designed to determine the reading strategy used by subjects must examine performance of individuals, rather than the mean for a group.

The effects of frequency and age of acquisition appear to be quite independent of the individual differences measured by the vocabulary score. The product SFI $X$ VOC was not an important predictor in either study; nor was AGE X VOC in Experiment 2. This suggests that both variables may affect a common stage of recognition that is not affected by word length. The effect of word length may be restricted to the stage at which the visual features are recoded into a functional stimulus for lexical retrieval. The individual differences may be related to the manner or efficiency with which this recoding is performed. Word frequency and age of acquisition may then determine the time required for the retrieval of lexical information. This would be quite consistent with the observation that word frequency (Oldfield, 1966) and age of acquisition (Carroll \& White, 1973) affect picture naming, but that word length has no effect (Oldfield, 1966) on the task. To our knowledge, no studies to date have considered the effect of age of acquisition on word recognition, but the effect merits further investigation since the effect of age appears to be independent of word frequency. It should be noted, however, that age may be a complex variable that is related to orthographic regularity, the child's vocabulary, or other variables that are considered in designing a reading program.

The inclusion of the vocabulary test in these studies accounts for some, but not all, of the individual differences. In Table 4, the optimal equation for the results of Experiment 1 accounted for only $22 \%$ of the 
total variance in the $\log (\mathrm{RT})$ scores. An alternative multiple regression, using the word variables plus 12 dummy variables coded for subjects, accounted for $59 \%$ of the variance. Roughly $37 \%$ of the variance is due to individual differences but cannot be accounted for by the differences on the vocabulary test. A similar pattern emerges with Experiment 2. With these results, only $17 \%$ of the total variance can be accounted for by the equations shown in Table 7. When these results were reanalyzed using mean $\log (\mathrm{RT})$, so that individual differences were ignored, an equation with age, length, and frequency accounted for only $55 \%$ of the total variance. In both studies, therefore, there are considerable individual differences, only some of which relate to the vocabulary measure. Another test, such as Baron and Strawson's (1976) test for knowledge of orthographic rules, could account for other differences and could show a different pattern of interaction with the word characteristics.

\section{REFERENCE NOTE}

1. Mewhort, D. J. K., \& Beal, L. Personal communication, August 1, 1978.

\section{REFERENCES}

Baron, J., \& Strawson, C. Use of orthographic and wordspecific knowledge in reading words aloud. Journal of Experimental Psychology: Human Perception and Performance, 1976, 2, 386-393.

Browning-Crinion, C., Dolmetsch, R., \& Mayzner, M. Variability in word-recognition performance. Bulletin of the Psychonomic Society, 1978, 11, 212-214.

Carroll, J. B., Davies, P., \& Richman, B. The American Heritage word frequency book. New York: American Heritage, 1971.

Carroll, J. B., \& White, M. N. Word frequency and age of acquisition as determiners of picture-naming latency. Quarterly Journal of Experimental Psychology, 1973, 24, 85-95.

Colegate, R. L., \& Eriksen, C. W. Implicit speech as an encoding mechanism in visual perception. American Journal of Psychology, 1970, 83, 208-215.

Eriksen, C. W., Pollack, M. D., \& Montague, W. E. Implicit speech: Mechanism in perceptual coding? Journal of Experimental Psychology, 1970, 84, 502-507.

Forster, K. I., \& Chambers, S. M. Lexical access and naming time. Journal of Verbal Learning and Verbal Behavior, $1973,12,627-635$.

Frederiksen, J. R., \& Kroll, J. F. Spelling and sound: Approaches to the internal lexicon. Journal of Experimental Psychology: Human Perception and Performance, 1976, 2 , 361-379.

Henderson, L., Coltheart, M., \& Woodhouse, D. Failure to find a syllabic effect in number naming. Memory \& Cognition, 1973, 1, 304-306.

Hirata, K., \& Bryden, M. P. Tables of letter sequences varying in order of approximation to English. Psychonomic Science, 1971, 25, 322-324.

It pays to increase your word power. Reader's Digest. September 1976, p. 4. (a)

It pays to increase your word power. Reader's Digest, October 1976, p. 6. (b)
KLAPP, S. T. Implicit speech inferred from response latencies in same-different decisions. Journal of Experimental Psychology, 1971, 91, 262-267.

Klapp, S. T., Anderson, W. G., \& Berrian, R. W. Implicit speech in reading, reconsidered. Joumal of Experimental Psychology, 1973, 100, 368-374.

KuĆERA, H., \& Francis, W. N. Computational analysis of present-day American English. Providence, R.I: Brown University Press, 1967.

LaBerge, D. A., \& Samuels, S. J. Toward a theory of automatic information processing in reading. Cognitive Psychology, 1974, 6, 293-323.

Mendenhall, W. Introduction to linear models and the design and analysis of experiments. Belmont, Calif: Duxbury Press, 1968.

Meyer, D. E., Schvaneveldt, R. W., \& Ruddy, M. G. Functions of graphemic and phonemic codes in visual word recognition. Memory \& Cognition, 1974, 2, 309-321.

Norman, C. The Queen's English: Standard of literacy among undergraduates in the Faculty of Arts and Science at Queen's University, 1975-1976. Kingston, Ont: Department of English, Queen's University, 1977.

OldFiELD, R. C. Things, words and the brain. Quarterly Journal of Experimental Psychology, 1966, 18, 340-353.

Raven, J. C. The Mill Hill Vocabulary Scale: Senior, Form 1. London: Lewis, 1943.

Rubenstein, H., Lewis, S. S., \& Rubenstein, M. A. Evidence for phonemic recoding in visual word recognition. Journal of Verbal Learning and Verbal Behavior, 1971, 10, 645-657.

SMITH, F. Understanding reading. Toronto: Holt, Rinehart, \& Winston, 1971.

SPOEHR, K. T., \& SMITH, E. E. The role of syllables in perceptual processing. Cognitive Psychology, 1973, 5, 71-89.

Sternberg, S. Memory-scanning: Mental processes revealed by reaction-time experiments. American Scientist, 1969, 57, 421-457.

Terry, P., Samuels, S. J., \& LaBerge, D. The effects of letter degradation and letter spacing on word recognition. Journal of Verbal Learning and Verbal Behavior, 1976, 15, 577-585.

TukeY, J. W. Quick and dirty methods in statistics: Part II. Simple analyses for standard designs. Proceedings of the Fifth Annual Convention, American Society for Quality Control, 1951, 189-197.

Webster's third international dictionary of the English language: Unabridged. Springfield, Mass: Merriam, 1966.

\section{NOTES}

1. We would like to thank D. J. K. Mewhort for this bon mot.

2. In Experiment 1, the mean RTs for word groups beginning with $C, N, R, S, T$, and $W$ were $678,645,644,636,650$, and $613 \mathrm{msec}$, respectively. While an analysis of variance showed an overall difference among the groups $[F(5,230)=2.816$, $\mathrm{p}<.05]$, a series of Tukey (1951) comparisons showed that only the difference between the $\mathrm{C}$ and $\mathrm{W}$ groups exceeded the critical difference of $51 \mathrm{msec}$ required for the .05 level of significance. These differences were ignored in the regression analyses in order to avoid the problems of adding five dummy variables. In Experiment 2, the mean RTs for the C, N, R, S, T, and $W$ groups were $715,695,684,717,739$, and $700 \mathrm{msec}$, respectively, and did not differ significantly $[F(5,144)=.57]$.

(Received for publication February 22, 1978; revision accepted February 1, 1979.) 